\title{
STUDYING THE FREQUENCY OF AUTOIMMUNE THYROID DISEASES IN DUHOK PROVINCE
}

\author{
Rozheen I. Hasan ${ }^{a^{*}}$, Amir H. Raziq ${ }^{b}$ \\ ${ }^{a}$ Duban Health Center, General Directorate of Duhok Health, Kurdistan Region, Iraq (rojin.selevany@gmail.com) \\ ${ }^{\mathrm{b}}$ Scientific Research Center, College of Sciences, University of Duhok, Kurdistan Region, Iraq (amir.razig@uod.ac)
}

\begin{abstract}
:
Thyroid disorders are one of the most frequent disorders affecting endocrine system. The present study aimed to identify the frequency of thyroid disorder in our locality at Duhok city. To do so, a total of one hundred patients and one hundred apparently healthy control individuals were enrolled in this study. Samples of venous blood $(5 \mathrm{ml})$ were withdrawn from patients and control subjects and analysed. Clinical assessment was performed by a specialist and each patient provided with a document supporting preliminary clinical diagnosis. Measurements of serum TSH, T3, T4, and anti-thyroperoxidase antibodies (anti-TPO antibodies) serum levels were performed. All assays were conducted at Duhok central health laboratory. Out of the one hundred patients and the one hundred control groups, fortytwo and thirty candidates were randomly selected, respectively. The mean TSH serum levels of 25.87 (uIU/ml) for the patients significantly differ from that of the control group $3.55(\mathrm{uIU} / \mathrm{ml})(p<0.001)$. However, T3 and T4 serum levels indicated no significant difference between the two categories. Moreover, there was statisticaly significant difference $(p<0.0001)$ between the patients and control groups when their mean serum anti-TPO concentrations were compared. In conclusion, considerable number of subjects appeared to be candidates for deranged thyroid functions and is susceptible to autoimmune thyroid disorder.
\end{abstract}

KEYWORDS: Autoimmune, Thyroid, Frequency, Anti-thyroperoxidase, thyroid stimulating hormone.

\section{INTRODUCTION}

Human autoimmune diseases are considered as a major health issue, affecting up to approximately $5 \%$ of the population and impose a significant morbidity and mortality burden on the human population. The causes beyond these diseases are still unidentified in many situations, although some general mechanisms can be responsible for initiating autoimmunity such as genetics, environment or even previous bacterial or viral infections. The pathogenesis of autoimmune diseases (AIDs) is activated by environmental factors and/or specific variants of specific genes (Ray et al., 2012).

Autoimmune thyroid diseases (AITDs) are relatively popular organ-specific autoimmune disorder. They encompass a category of pathologies embarked on by the immune tolerance failure to thyroid antigens and involved the inflammation of the thyroid gland. Many of these situations have been described, such as Hashimoto's thyroiditis (HT), Grave's disease (GD), painless thyroiditis, postpartum thyroiditis, and sub-acute thyroiditis. Histologically, there is lymphocytic infiltration in the thyroid tissue and autoreactive response is directed against thyroid autoantigens; as well as production of specific autoantibodies, which can be directed against thyroid peroxidase (Anti-TPO), thyroglobulin, and/or thyroid stimulating hormone receptor (Swain et al., 2005).

In HT the thyroid follicular cells are destroyed such that insufficient levels of thyroid hormones (THs) are produced, leading to hypothyroidism while in Graves' disease, the gland becomes hyperactive and overproduces THs (Mak and Saunders, 2006). These disorders share many immunological features and the disease may progress from one state to another as the autoimmune process evolves.

Thyroid stimulating hormone (TSH) is the most common required thyroid function test and is recommended for initial screening (Spencer et al., 1993). While all analytical platforms will not produce precisely equivalent TSH values, the reference range for TSH in healthy iodine-abundant individuals is almost quite analogous at between

$0.4-4.0 \mathrm{mIU} / \mathrm{L}$ even in various geographic and ethnic populations (Li et al., 2014).

Concerning thyroid hormones (tri-iodothyronine T3 and tetraiodothyroxine T4) and TSH, high level of T3 and T4 hormones and low level of TSH hormone were reported for hyperthyroidism, while the inverse values indicates hypothyroidism (Al-Mofarji, 2013). Moreover, the elevated TSH levels accompanied by normal T3 and T4 levels may be attributed to the deficiency of iodine especially in older age. The primary functional consequence of iodine shortage is an increased iodine uptake by the thyroid; this process is potentiated by the increasing level of serum TSH (Hoogendoorn et al., 2006). Similar manifestation of altered TSH profile in association with normal thyroid hormone levels may also attributed to subclinical hypothyroidism and subclinical hyperthyroidism (Cappa et al., 2011).

Anti-thyroid peroxidase (TPO) antibodies emerge against a transmembrane protein of thyrocytes engaged in the generation

\footnotetext{
* Corresponding author

This is an open access under a CC BY-NC-SA 4.0 license (https://creativecommons.org/licenses/by-nc-sa/4.0/)
} 
of thyroid hormones. Anti-TPO antibodies (previously identified as anti-thyroid microsomal antibodies) and anti-thyroglobulin antibodies are important diagnostic biomarkers for AITDs as they are found in more than $80 \%$ cases of Graves' disease and over 90\% cases of Hashimoto's thyroiditis (Stathatos and Daniels, 2012). The anti-TPO antibody is more sensitive marker for autoimmune thyroid dysfunction than $\mathrm{Tg}$ (thyroglobulin) antibody (Demers and Spencer, 2003). It was suggested that the anti-TPO antibody titers are associated with the extent of lymphocytic infiltration of thyroid tissue. Oxidative stress, manifested by reduced antioxidant potential, can be indicated by anti-TPO antibodies, development of glycosylation products and $\mathrm{O}_{2}$ metabolic by-product in blood (Ruggeri et al., 2016).

The aim of this work was to estimate the incidence of autoimmune thyroid diseases in Duhok province.

\section{MATERIALS AND METHODS}

A total of 100 patients; with suspected thyroid disease, were enrolled in the study, their ages ranged from 7-68 years old. To achieve comparisons of measured parameters, a total of 100 apparently healthy subjects were randomly selected as a control group. Sex and age of these subjects were nearly comparable to that of the patients. Candidate subjects where those who attended local official and private health facilities during a period from April to October 2018. Clinical assessment was performed by a specialist and each patient provided with a document supporting preliminary clinical diagnosis. Venous blood $(5 \mathrm{ml})$ was collected from each patient and healthy control, centrifuged at 3000 round per minute (rpm) for 10 minutes to obtain sufficient amount of serum.

The measurements of serum thyroid stimulating hormone (TSH), tri-iodothyronine (T3), and thyroxine (T4) levels were performed immunoassay test by Cobas e411 Analyser (Roche, USA) using T3, T4, and THS measurement kits (Elecsys ${ }^{\circledR}$, USA) while antithyroperoxidase (anti-TPO) antibodies serum level measured by ELISA method at wavelength $450 \mathrm{~nm}$ using Anti-TPO measurement kit (AESKULISA ${ }^{\circledR}$, Germany).

In addition, out of the one hundred diseased individuals and the one hundred control group, forty-two and thirty candidates were randomly selected, respectively. Procedure followed the manufacturer's instructions and all assays were conducted at Duhok central public health laboratory.

All data were analyzed by the SPSS (IBM Corporation, New York, NY, USA) statistical package (Version 23.0).

\section{RESULTS}

Following clinical assessment for patients presented to the clinical and laboratory investigation; and these include, one hundred showing TSH profile below normal range $(0.27 \mathrm{uIU} / \mathrm{ml})$ (Considered Hyperthyroidism) while hypothyroidism was manifested by TSH serum level exceeding the normal range value (4.2 uIU/ml). One hundred controls were also included as per their normal serum TSH level.

The forty-two individuals $(58.3 \%)$ were regarded as diseased according to their TSH profile (below $0.27 \mathrm{uIU} / \mathrm{ml}$ or above 4.2 $\mathrm{uIU} / \mathrm{ml}$ ) and thus subjected for further laboratory investigation and eventually proven to be an autoimmune thyroid patients due to their elevated Anti-TPO level $(<34 \mathrm{IU} / \mathrm{ml})$, on the other hand thirty individuals $(41.7 \%)$ were considered normal control according to the same criteria (Table 1).
Table 1. Frequency of thyroid disease in patients and control groups

\begin{tabular}{|c|c|c|c|}
\hline Group & Freq. & Percent (\%) & $\begin{array}{c}\text { Valid } \\
\text { Percent (\%) }\end{array}$ \\
\hline Case & 42 & 58.3 & 58.3 \\
\hline Control & 30 & 41.7 & 41.7 \\
\hline Total & 72 & 100.0 & 100.0 \\
\hline
\end{tabular}

It was shown that the age of $5.6 \%$ of the patients and control ranged between $1-14$ years, $12.5 \%$ of the two groups' ages were equal to or more than 45 years, and the highest percentage of participants (81.9\%) aged between 15-44 years (Table 2).

Table 2. Frequency of patients and controls according to age in the study sample

\begin{tabular}{|c|c|c|c|c|c|c|}
\hline \multirow{2}{*}{ Age group } & \multicolumn{2}{|c|}{ patients } & \multicolumn{2}{c|}{ control } & \multicolumn{2}{c|}{ Total } \\
\cline { 2 - 7 } & Freq. & $\begin{array}{c}\text { Percen. } \\
(\%)\end{array}$ & Freq. & $\begin{array}{c}\text { Percen. } \\
(\%)\end{array}$ & Freq. & $\begin{array}{c}\text { Percen. } \\
(\%)\end{array}$ \\
\hline $1-14$ & 2 & 4.8 & 2 & 6.7 & 4 & 5.6 \\
\hline $15-44$ & 33 & 78.6 & 26 & 86.67 & 59 & 81.9 \\
\hline $45-$ more & 7 & 16.7 & 2 & 6.67 & 9 & 12.5 \\
\hline Total & 42 & 100.0 & 30 & 100 & 72 & 100.0 \\
\hline
\end{tabular}

It was found that females represented $76.2 \%$ of the selected patient individuals while $23.8 \%$ of the candidates were males. Moreover, $40 \%$ females and $60 \%$ males stood for the control group. In general, males represented $38.9 \%$ of patients and control groups while females created $61.1 \%$ of the two groups (Table 3).

Table 3. Frequency of patients and control groups according to gender in the study sample

\begin{tabular}{|c|c|c|c|c|c|c|}
\hline \multirow{2}{*}{ Gender } & \multicolumn{2}{|c|}{ Patients } & \multicolumn{2}{c|}{ Controls } & \multicolumn{2}{c|}{ Total } \\
\cline { 2 - 7 } & Freq. & $\begin{array}{c}\text { Percen. } \\
(\%)\end{array}$ & Freq. & $\begin{array}{c}\text { Percen. } \\
(\%)\end{array}$ & Freq. & $\begin{array}{c}\text { Percen. } \\
(\%)\end{array}$ \\
\hline Male & 10 & 23.8 & 18 & 60 & 28 & 38.9 \\
\hline Female & 32 & 76.2 & 12 & 40 & 44 & 61.1 \\
\hline Total & 42 & 100.0 & 30 & 100 & 72 & 100.0 \\
\hline
\end{tabular}

The results of the current work showed mean TSH serum levels of $25.87(\mathrm{uIU} / \mathrm{ml})$ for the patients which greatly surpass that of the control group $3.55(\mathrm{uIU} / \mathrm{ml})$ and it was statistically significantly different $(p<0.001)$. While both T3 and T4 mean serum levels of $2.04(\mathrm{nmol} / \mathrm{l}), 1.5(\mathrm{nmol} / \mathrm{l})$; and $96.0(\mathrm{nmol} / \mathrm{l})$, $103.56(\mathrm{nmol} / \mathrm{l})$ were recorded for patients and control groups, respectively. The later finding indicated no significant differences between the two categories (Table 4).

Table 4. Serum levels of thyroid hormones in patients and control groups $($ mean \pm SD)

\begin{tabular}{|c|c|c|c|c|c|}
\hline $\begin{array}{l}\text { Thyroid } \\
\text { hormones }\end{array}$ & Group & No. & $\begin{array}{l}\text { Mean serum } \\
\text { concentration }\end{array}$ & $\begin{array}{l}\text { Std. } \\
\text { Deviation }\end{array}$ & $\begin{array}{c}p \\
\text { value }\end{array}$ \\
\hline TSH & Case & 42 & 25.87 & 34.2 & \multirow{2}{*}{0.001} \\
\hline (uIU/ml) & Control & 30 & 3.55 & 8.8 & \\
\hline T3 & Case & 42 & 2.04 & 2.3 & \multirow{2}{*}{0.05} \\
\hline$(\mathrm{nmol} / \mathrm{l})$ & Control & 30 & 1.50 & 0.5 & \\
\hline $\mathrm{T} 4$ & Case & 42 & 96.00 & 58.6 & \multirow{2}{*}{0.05} \\
\hline$(\mathrm{nmol} / \mathrm{l})$ & Control & 30 & 103.56 & 44.4 & \\
\hline
\end{tabular}

Furthermore, the mean serum concentration of anti-TPO was $222.43(\mathrm{IU} / \mathrm{ml})$ for the thyroid patients group while the mean of anti-TPO serum conc. was 6.0 (IU/ml) for the control group. It is also shown that both disease and control group were highly statistically significantly different $(p<0.000)$ when mean serum levels of anti-TPO were compared (Table 5). 
Table 5. Serum concentration of anti-TPO for patients and control groups (mean \pm SD)

\begin{tabular}{|c|c|c|l|c|c|}
\hline & Group & $\begin{array}{l}\text { Numbe } \\
\mathrm{r}\end{array}$ & $\begin{array}{l}\text { Std. } \\
\text { Deviatio } \\
\mathrm{n}\end{array}$ & $\begin{array}{c}\text { Mean Anti- } \\
\text { TPO serum } \\
\text { concentratio } \\
\mathrm{n}(\mathrm{IU} / \mathrm{ml})\end{array}$ & $\begin{array}{c}p \\
\text { valu } \\
\mathrm{e}\end{array}$ \\
\hline $\begin{array}{c}\text { Anti } \\
- \\
\text { TPO }\end{array}$ & \begin{tabular}{c} 
Case \\
\cline { 2 - 6 }
\end{tabular} & 42 & 280.6 & 222.4 & 0.00 \\
0
\end{tabular}

\section{DISCUSSION}

Many studies stated that the majority of thyroid diseases are widespread in adults aged between 30 to 50 years old (Gabriel et al., 2009; Al-hindawi et al., 2017). This observation is supported by the general consensus of an increased thyroid disorders incidence rates with advanced patients' ages (Vadiveloo et al., 2013)

The results of the present study were in line with those of $\mathrm{AL}$ Ramahi (2011), and Al-Hindawi et al., (2017) who reported that $52 \%$ and $43.33 \%$ of AITD patients were in the age group of $30-$ 50 years, respectively. Furthermore, Sindi et al., (2018) claimed younger ages for their selected patients to involve subjects between 20-29 and 30-39 years for whom the incidence of AITD was $30 \%$ and $34 \%$ of all participants, respectively.

Autoimmune diseases influence approximately $8 \%$ of the population; women represent $78 \%$ of the victims. The reason for the high prevalence in women is unclear despite the many theories proposed for clarification of this fact. Females are known to interact with trauma, vaccination, and infection with exaggerated antibody secretion and a predominance $\mathrm{T}$ helper (Th2) immune reaction, However Th1 response and inflammation are often more extreme in males. Females have comparable number of lymphocytes but higher potential for antibody generation by B cells. As well as, females have much more vigorous humoral and cellular immune reactions and greater than normal CD4+ T cell level following immunization (Fairweather et al., 2008). Sex differences in immune response and the prevalence of autoimmune diseases are believed to be mediated by steroid sex hormones such as progesterone, testosterone, and, estrogen. Estrogens and androgens directly affect the immune response by interacting with hormone receptors on the surface of immune cells. As a general rule, estrogens stimulate the immune reactions, while progesterone and testosterone may perform an immunosuppressive function (Brunelleschi, 2015). Likewise, cytokine receptors (eg, IL-1R, IL-18R) are present on hormone-producing cells, suggesting bidirectional mode of control over the immune function. Furthermore, the direct impact of sex hormone on target tissues or organs must be considered when sex difference mediated immune response is to be evaluated (Straub, 2007; Kublickiene and Luksha, 2008).

The greater incidence of autoimmune diseases in subjects with structural X-chromosome deformities and monosomy implies an essential function for the X-chromosome in the development of autoimmune response. In females, one of the two Xchromosomes is inhibited in each cell. Often, the ratio is 50:50 for maternal and paternal X-chromosomes. On the other hand, in certain females a skewed inhibition is manifested that may result in insufficiently increased amounts of particular antigens to stimulate self-tolerance. In agreement with this general paradigm, skewed X-chromosome inhibition has been almost observed in females with autoimmune thyroid diseases with a correlation of OR 2.54 for GD and 2.40 for HT (Effraimidis and Wiersinga, 2014).
The Y-chromosome is less significant for endurance because it contains only a little number of genes. Nevertheless, Ychromosome absence has been observed in Grave's disease and Hashimoto's thyroiditis patients and is manifested by diminished levels of testosterone. The fewer number of genes not associated with fertility aspects of the males are X-chromosome homologs with correspondent rule in immune reactions (Persani et al., 2012). The loss may lead to haplo-insufficiency identical to loss of X-chromosome, and an imbalance for the alleles in common with the X-chromosome may unfold. Furthermore, the correlation between thyroid and testosterone through regulation of sexhormone binding globulin can be an additional attribute (Meikle, 2004). Elevated thyroid hormone levels raise the levels of free testosterone with consequent physiological impacts. Changes in hormone levels such as an excess testosterone in women with polycystic ovary syndrome increase the prevalence of AITDs (Janssen et al., 2004). More recently, it was found out that tiny non-coding microRNAs (miRNAs) alter post-transcriptional gene expression by interacting with messenger RNAs and are emerging as novel key factors in autoimmune diseases. The $\mathrm{X}$ chromosome (but not the $\mathrm{Y}$ chromosome) is greatly enriched for miRNAs, whose ultimate expression can be controlled by estrogens: an abnormal miRNA expression profile has been reported in certain autoimmune diseases (Munoz-Culla et al., 2016).

The results of the current study were in line with many other who demonstrated the inverse relation between TSH and thyroid hormones (Senthilkumaran et al., 2015; Hasan et al., 2016; and Panti et al., 2018). Moreover, it was found that the levels of serum T3 and T4 were significantly elevated in GD patients when compared to the healthy individuals and TSH level showed an opposite value for the two groups (Veeramuthumari et al., 2010). Researchers interested in studying the correlation of TSH, T3, and T4 levels and thyroid disorders usually found that TSH levels in hypothyroidism were more than the normal range (ALRamahi, 2011). It is fairly documented that the serum TSH level is increased in primary hypothyroidism and its measurement is an optimal screening test for dysfunction of the thyroid. Serum FT3 may remain within the optimal range because of the exaggerated conversion of FT4 to FT3 by type 2 deiodinase and the preferential release of FT3 by residual thyroid tissue under the effect of elevated TSH levels (Bianco et al., 2002). For these reasons, estimation of the serum T3 and FT3 levels is not beneficial for the diagnosis or monitoring of subjects with primary hypothyroidism (Foley Jr., 1998). However, Jayan et al., (2015) suggested that an elevated TSH level is implicated as early evidence of a reduced thyroid reserve and in conjunction with diminished fT3 and fT4 is diagnostic of primary overt hypothyroidism.

Aging can also complicate the view as it significantly reduces serum T4 in male and female and therefore imposing additional restrictions for the conclusive interpretation of hormonal findings (Corrêa da Costa and Rosenthal, 1996).

In essence, anti-thyroid antibodies are associated with the underlying pathogenesis of autoimmune thyroiditis through complement-dependent cytotoxicity (Miko's et al., 2014); hence, their occurrence may certainly be identified in advance to the manifestation of clinical disease of the thyroid or faulty thyroid function tests by many years (Hutfless et al., 2011). Since autoantibodies against thyroid tissue have been found in normal healthy subjects predominately females, follow-up thyroid hormone profile investigation in autoantibodies positive candidates is extremely substantial for creating time-related diagnosis (McLeod and Cooper, 2012). Moreover, Lock et al., (2004) highlighted the paramount paradigm of considering anti- 
TPO antibody level estimation as an integral portion of clinical investigation of subjects with autoimmune thyroid diseases.

The results of the current study were almost similar to many others who claimed that elevation of anti-thyroid antibodies is associated with deranged TSH level (Brown et al., 2016; Loh et al., 2016; Al-Rabia, 2017). They were also compatible to two others conducted in Brazil and India which both showed the direct association between autoimmune thyroid diseases and the elevated anti-TPO (Silva et al., 2003; Unnikrishnan et al., 2013). Similarly, an apparent rise in prevalence was noted in the southern part of India. The corresponding prevalence of anti-TPO positivity noted in two different studies conducted in Kerala and Chennai were $16.7 \%$ and $25.81 \%$, respectively (UshaMenon et al., 2009; Marwaha et al., 2012).

Similar outcomes have been reported in the present work to that conducted in Iran by Ghoraishian et al., (2006), the later investigated the association of anti-TPO with TSH, T4, and T3 in 2425 subjects and found hormones serum values to be effectively deranged in antibody positive category. Although the previous study confirmed that anti-TPO antibodies are predominately exist in subjects with abnormal TSH, it was difficult to prove a direct relationship between serum levels of these biological markers. Anti-thyroid autoantibodies essentially demonstrate their harmful impact through complement-dependent cytotoxicity and the association between existence of autoantibodies and commencement of future thyroid disorders is complex (McLachlan and Rapoport, 2007).

\section{CONCLUSIONS}

It is concluded that thyroid gland disorders constitute a major health issue and considerable number of people are susceptible to develop autoimmune thyroid disorder. Middle aged individuals represented the most frequently affected subjects by autoimmune thyroid disorders with females being the greater candidates for the conditions and thus it is implied that sex biased disease condition and age preference were attained.

\section{REFERENCES}

Al-hindawi, S.H.; Al-ghurabi, B. H. andLuaibi, N. M. (2017). The role of hla-drb1 allele in hypothyroid patients with and without periodontitis. Pak. J. Biotechnol.,14 (4): 629-634.

Al-Mofarji, S. T. K. (2013). The Relationship between Thyroid Disorders and Helicobacter pylori Infection. M.Sc thesis. Al-Nahrain University.

Al-Rabia, M. W. (2017). Correlation of thyroid antibodies with TSH, T3 and T4 hormones in patients diagnosed with autoimmune thyroid disorders. Pakistan Journal of Pharmaceutical Sciences, 30(2): 607-612.

Al-Ramahi, I. J. K.(2011). Molecular and Genetic Study in samples of Iraqi patients with Thyroid Disorders. PhD thesis. University of Baghdad. Baghdad, (81-84).

Bianco, A. C.; Salvatore, D.; Gereben, B.; Berry, M. J. and Larsen, P. R. (2002). Biochemistry, cellular and molecular biology, and physiological roles of the iodothyronine selenodeiodinases. Endocrine Reviews, 23(1): 38-89.

Brown, S. J.; Bremner, A. P. and Hadlow, N. C. (2016). The log TSHfree T4 relationship in a community-based cohort is nonlinear and is influenced by age, smoking and thyroid peroxidase antibody status. Clinical Endocrinology, 85( 5): 789-796.

Brunelleschi, S. (2015). Review: Immune response and auto-immune diseases: gender does matter and makes the difference. Ital. J. Gender-Specific Med., 2(1): 5-14.

Cappa, M.; Bizzarri, C. and Crea, F. (2011). Autoimmune Thyroid Diseases in Children. Journal of Thyroid Research: 1-13.
Corrêa da Costa, V. M. and Rosenthal, D. (1996 ). Effect of ageing on thyroidal and pituitary T4 5 deiodinase activity in female rats. Life Sciences, 59: 1515-1520.

Demers, L. M. and Spencer, C. A. (2003). Laboratory medicine practice guidelines: laboratory support for the diagnosis and monitoring of thyroid disease. Clin. Endocrinol., 58 (2): 138140.

Effraimidis, G. and Wiersinga W. M. (2014). Mechanisms in endocrinology: autoimmune thyroid disease: old and new players. Eur. J. Endocrinol., 170: 241-252.

Fairweather, D.; Frisancho-Kiss, S. and Rose, N. R. (2008). Sex Differences in Autoimmune Disease from a Pathological Perspective "A Review". The American Journal of Pathology, 173 (3): 600-609.

Foley Jr., T. P. (1998). Mediators of thyroid diseases in children. Journal of Pediatrics, 132(4): 569-570.

Gabriel, B.; Thomas, A.; Kent, F. and Talavera, M. S. (2009). Thyroid Disease. Staff Neurologist, Neurology Service, Philadelphia Veterans. Affairs. Medical Center. Med. Rep., 8(1): 16-19.

Ghoraishian, S. M.; Hekmati Moghaddam, S. H. and Afkhami- Ardekani, M. (2006). Relationship between anti-thyroid peroxidase antibody and thyroid function test. Iranian Journal of Immunology, 3(13): 146-149.

Hasan, B. F.; Al Hudak, N. and Abd, I. D. (2016). Estimation of thyroid hormones and liver enzymes in hypo and hyperthyroidism in Iraqi women. Int. J. Pharm. Bio. Sci., 7(4): B707 -713.

Hoogendoorn, E.H.; Hermus, A. R. and Kiemeney, L. A. (2006). Thyroid function and prevalence of anti- thyroperoxidase antibodies in a population with borderline sufficient iodine intake: influences of age and sex. Clin. Chem., 52: 104-111.

Hutfless, S. M.; Matos, P.; Talor, M. V.; Caturegli, P. and Rose, N. R. (2011). Significance of prediagnostic thyroid antibodies in women with autoimmune thyroid disease. Journal of Clinical Endocrinology \& Metabolism, 96( 9): E1466-E1471.

Janssen, O. E.; Mehlmauer, N.; Hahn, S.; Offner, A. H. and Gartner, R. (2004). High prevalence of autoimmune thyroiditis in patients with polycystic ovary syndrome. Eur. J. Endocrinol., 150: 363-369.

Jayan, A., Gautam, N.; Dubey, R. K.; Neupane, Y.; Padmavathi, P.; Jha, S. K. and Sinha, A. K. (2015). Prevalence and impact of thyroid disorders based on TSH level among patients visiting tertiary care hospital of South Western. Nepal. Nepal. Med. Coll. J., 17(1-2): 6-10.

Kublickiene K. and Luksha L. (2008). Gender and the endothelium. Pharmacol. Rep., 60: 49-60.

Lin, L.; Hungs, M. and Mignot, E. (2001 ). Narcolepsy and the HLA region. J. Neuroimmunol., 117: 9-20.

Lock, R. J.; Marden, N. A.; Kemp, H. J.; Thomas, P. H.; Goldie, D. J. and Gompels, M. M. (2004). Subclnical hypothyroidism: a comparison of strategies to achieve adherence to treatment guidelines. Ann. Clin. Biochem., 41(Pt 3): 197.

Loh, T. P.; Tee, J. C. S.; Tee, N. W. S.; et al. (2016). Association between thyroid function tests and anti-thyroid peroxidase (TPO) antibodies in pregnancy. Endocrine Journal, 53(3): 865-867.

Mak, T.W. and Saunders M.E. (2006). The Immune Response:Basic and Clinical Principles. San Diego: Elsevier.

Marwaha, R. K.; Tandon, N.; Ganie, M. A.; Kanwar, R.; Garg, M. K. and Singh, S. (2012). Status of thyroid function in Indian adults: Two decades after universal salt iodization. J. Assoc. Physicians India., 60: 32-36.

McLachlan, S. M. and Rapoport, B. (2007). Thyroid peroxidase as an autoantigen. Thyroid, 17(10): 939-948.

McLeod D. S. and Cooper, D. S. A. (2012). The incidence and prevalence of thyroid autoimmunity. Endocrine Journal, 42(2): 252-265.

Meikle, A. W.(2004). The interrelationships between thyroid dysfunction and hypo-gonadism in men and boys. Thyroid 14(Suppl 1): S17-25.

Miko's, H.; Miko's, M.; Obara-Moszy'nska, M. and Niedziela, M. (2014). The role of the immune system and cytokines involved in the pathogenesis of autoimmune thyroid disease (AITD). Endokrynologia Polska, 65(2): 150-155.

Muñoz-Culla, M.; Irizar, H.; Muñoz-Cuesta, M.; Castillo-Triviño, T.; Osorio-Querejeta, I.; Sepúlveda, L.; López de Munain, A.; 
Olascoaga, J. and Otaegu, D. (2016). SncRNA (microRNA and snoRNA) opposite expression pattern found in multiple sclerosis relapse and remission is sex dependent. Scientific Report; 6(20126).

Panti, P.; Choudhary, T.; Sekhri, T.; Kanwar, R. and Uniyal, N. (2018). Study of correlation between vaitamin D deficiency and antithyroperoxidase antibodies in AITDs. Juornal of Medical Academics, 1(1): 10-14.

Persani, L.; Bonomi, M.; Lleo, A.; Pasini, S.; Civardi, F.; Bianchi, I.; et al. Increased loss of the $\mathrm{Y}$ chromosome in peripheral blood cells in male patients with autoimmune thyroiditis.. (2012). Increased loss of the $\mathrm{Y}$ chromosome in peripheral blood cells in male patients with autoimmune thyroiditis. J. Autoimmun., 38: J193-196.

Ray, S.; Sonthalia, N.; Kundu, S. and Ganguly, S. (2012). Autoimmune Disorders: An Overview of Molecular and Cellular Basis in Today's Perspective. Journal of Clinical \& Cellular Immunology, S10(003): 1-12.

Ruggeri, R. M.; Vicchio, T. M.; Cristani, M.; Certo, R.; Caccamo, D.; Alibrandi, A.; et al. (2016). Oxidative stress and advanced glycation end products in Hashimoto's thyroiditis. Thyroid, 26: 504-511.

Senthilkumaran, S.; Sathyaprakash V. and Sundhararajan A. (2015). A Study on Prevalence and Distribution of Subclinical Hypothyroidism in Rural Women. Sch. J. Appl. Med. Sci., 3(1D): 287-290.

Silva, L. M.; Chavezm J.; Canalli, M. H. B. and Zanetti, C. R. (2003). Determination of $\mathrm{IgG}$ subclasses and avidity of antithyroid peroxidase antibodies in patients with subclinical hypothyroidism - a comparison with patients with overt hypothyroidism. Horm. Res., 59(3): 118-124.

Sindi, H. A.; Yousef, F. M. and Aljahdali, B. A. (2018). Vitamin D Status and Autoimmune Disease (Hashimoto's Thyroiditis) in Saudi
Arabian Women. International Journal of Pharmaceutical and Phytopharmacological Research (eIJPPR), 8(1): 21-26.

Spencer, C. A.; Schwarzbein, D.; Guttler, R. B.; LoPresti, J. S. and Nicoloff, J. T. (1993). Thyrotropin (TSH)-releasing hormone stimulation test responses employing third and fourth generation TSH assays. J. Clin. Endocrinol. Metab.,76: 494498.

Stathatos, N. and Daniels, G. H. (2012). Autoimmune thyroid disease. Current Opinion in Rheumatology, 24(1): 70-75.

Straub, R. H. (2007). The complex role of estrogens in inflammation. Endocrine Rev., 28: 521-574.

Swain, M.; Swain, T and Mohanty, B. K. (2005). Autoimmune thyroid disorders - an update . Indian Journal of Clinical Biochemistry, 20 (1): 9-17.

Unnikrishnan, A. G.; Kalra, S.; Sahay, R. K.; Bantwal, G.; John, M. and Tewari, N. (2013). Prevalence of hypothyroidism in adults: An epidemiological study in eight cities of India. Indian Journal of Endocrinology and Metabolism., 17(4): 647-652.

UshaMenon, V., Sundaram, K. R.; Unnikrishnan, A. G.; Jayakumar, R. V.; Nair, V. and Kumar, H. (2009). High prevalence of undetected thyroid disorders in an iodine sufficient adult south Indian population. J. Indian Med. Assoc., 107: 72-77.

Vadiveloo, T.; Donnan, P.; Murphy, M. and Leese, G. (2013). Age and gender specific TSH reference intervals in people with no obvious thyroid disease in Tayside,Scotland :the thyroid epidemiology and research study. J. Cli. Endocrinol. Metab., 98(3): 1147-1153.

Veeramuthumari, P.; Isabel W. and Kannan, K. (2011). A study on the level of T3, T4, TSH and the association of $\mathrm{A} / \mathrm{G}$ polymorphism with CTLA-4 gene in Graves' Hyperthyroidism among south Indian population. Ind. J. Clin. Biochem., 26(1): 66-69. 